\title{
Hygrothermal Performance Difference of Wooden Beam Embedded in an Internally Insulated Masonry Wall in 2D and 3D Models
}

\author{
Xiaohai Zhou ${ }^{1,2}$, Jan Carmeliet ${ }^{2}$ and Dominique Derome ${ }^{3}$ \\ ${ }^{1}$ Laboratory of Multiscale Studies in Building Physics, Empa, Dübendorf, Switzerland, \\ xiaohai.zhou@empa.ch \\ ${ }^{2}$ Chair of Building Physics, ETH Zürich, Zürich, Switzerland, cajan@ethz.ch \\ ${ }^{3}$ Department of Civil and Building Engineering, Université de Sherbrooke, Sherbrooke, Canada, \\ dominique.derome@USherbrooke.ca
}

\begin{abstract}
Internal insulation of masonry walls may significantly increase the decay risk of embedded wooden beams due to lower temperature and consequently lower drying potential in the existing wall. Since high moisture contents will affect the performance and service life of wood, the study of moisture-related damage problems in wooden beam-ends in internally insulated masonry walls is of great importance. In the previous studies, the numerical study of hygrothermal performance of wooden beam-ends is performed only with $2 D$ models. In this paper, we study whether a $2 D$ numerical model can represent accurately the $3 D$ hygrothermal behavior of wooden beam-ends. Therefore, the difference between $2 D$ and $3 D$ model results of the hygrothermal performance of wooden beam-ends embedded in an internally insulated masonry wall is analyzed. The difference of temperature and relative humidity in wooden beam-end between $2 D$ and $3 D$ models is in general small. However, $2 D$ hygrothermal models show much lower relative humidities and thus lower moisture risk at some locations in the wooden beam-end. We find that a $3 D$ hygrothermal model more accurately simulates the hygrothermal behavior.
\end{abstract}

Keywords: Interior Thermal Insulation, Wooden Beam, 2D Modeling, 3D Modeling.

\section{Introduction}

Many historical buildings are built with solid brick walls and wooden beam constructions. These buildings are mostly not energy efficient and represent a significant energy-saving potential. For some historical buildings with a worth-preserving facade, the only possible energy renovation measure is internal wall insulation. Internal insulation of masonry walls may significantly increase the moisture-related damage risk of building materials and components due to lower temperature and consequently lower drying potential in the existing wall ( Morelli and Svendsen, 2013; Harrestrup and Svendsen, 2016; Zhou et al., 2017; Zhou et al., 2018). The floors in old masonry buildings are often carried by wooden beams embedded in the brick. The study of moisture-related problems in wooden beam-ends in internally insulated masonry walls is of high practical and scientific importance (Kehl et al., 2013).

Field investigation and numerical study both indicate that exterior render affects water uptake by external walls during wind driving rain events ( Künzel et al., 2004; Pazera and Bomberg, 2010; Guizzardi et al., 2015; Zhou et al., 2018). Exterior renders with high liquid water permeability tend to lead to high moisture contents in the masonry. It is important to study the hygrothermal behavior and durability risk of wooden beam-ends after internal 
insulation for renders with different rain protection.

Moisture and heat transport in masonry wall with wooden beam is in reality a threedimensional problem. However, many studies use only 2D hygrothermal models to study the moisture risk of wooden beam-ends in internally insulated masonry (Johansson et al., 2014; Guizzardi et al., 2015; Harrestrup and Svendsen, 2016). In a 2D model, wooden beam is assumed to have the same width as the wall envelope. However, in reality, the width of wooden beam is much smaller compared to that of wall envelope. It is still an open question whether a simplified 2D numerical model can represent accurately the hygrothermal conditions as modelled in 3D. The aim of this paper is to compare 2D and 3D hygrothermal modelling of the hygrothermal performance of wooden beam-ends embedded in an internally insulated masonry wall.

\section{Modelling}

\subsection{Methodology}

Because of modelling restriction, it is hardly feasible to model all bricks and mortar joints of a masonry wall in $3 \mathrm{D}$, since it would lead to very large meshes and high computational costs. Therefore, some simplifications are needed to model the masonry wall in 3D. First, a 2D model with a detailed distribution of bricks and mortar joints is built. Then a 2D model with simplified distribution of bricks and mortar joints is built and compared with the detailed 2D model. The simulated results from these two 2D modeis are compared and discussed. Finally,
based on results of the simplified 2D model, a simplified 3D nodel is developed.
A typical masonry wall structure of Switzeriand is considered for this analysis. The
geometry of the 2D model with detailed distribution of bricks and mortar joints is shoyn in
Figure 1. The 2D model comprises from exterior to interior in an exterior render, a masonry
wall (three wythes of brick), an original interior plaster, an aerogel-based insulation layer and a new interior plaster layer. In the geometry, there is a 1-cm thick air gap at the wooden

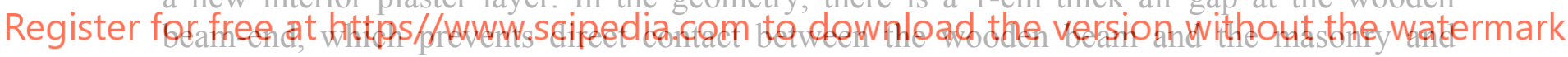

functions capillary break. A simplified 2D model of this wall is shown in Fig. 2, where the horizontal mortar joints are negiected. The horizontal mortar joints have much smaller liquid permeability compared to brick. Liquid water bypasses the horizontal mortar joints and transports to the inside mainly through brick. The vertical joints are however barriers to liquid transport and have to be considered. The 3D model follows the geometry of the simplified 2D model (Figure 3). In 3D, the width of masonry wall is $100 \mathrm{~cm}$ and the width of wooden beam is $20 \mathrm{~cm}$.
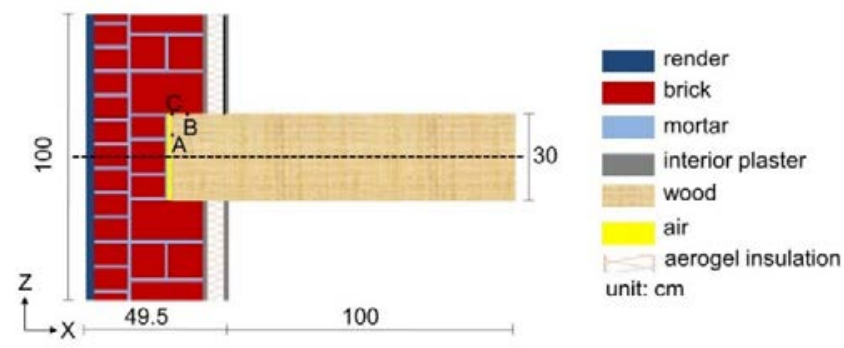

Figure 1. A detailed 2D schematic representation of wooden beam in an internally insulated masonry wall. 

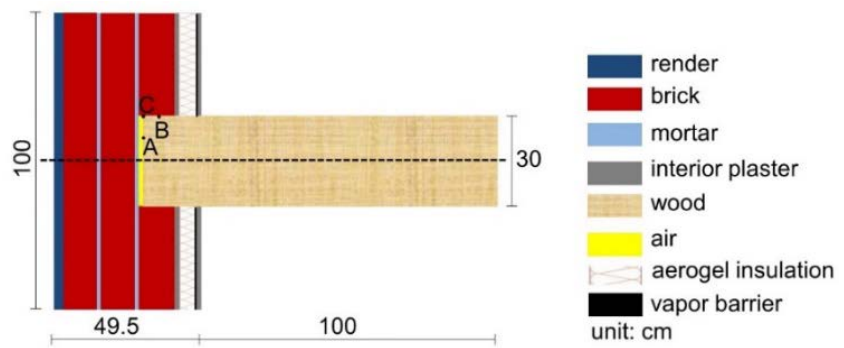

Figure 2. A simplified 2D schematic representation of wooden beam in an internally insulated masonry wall.

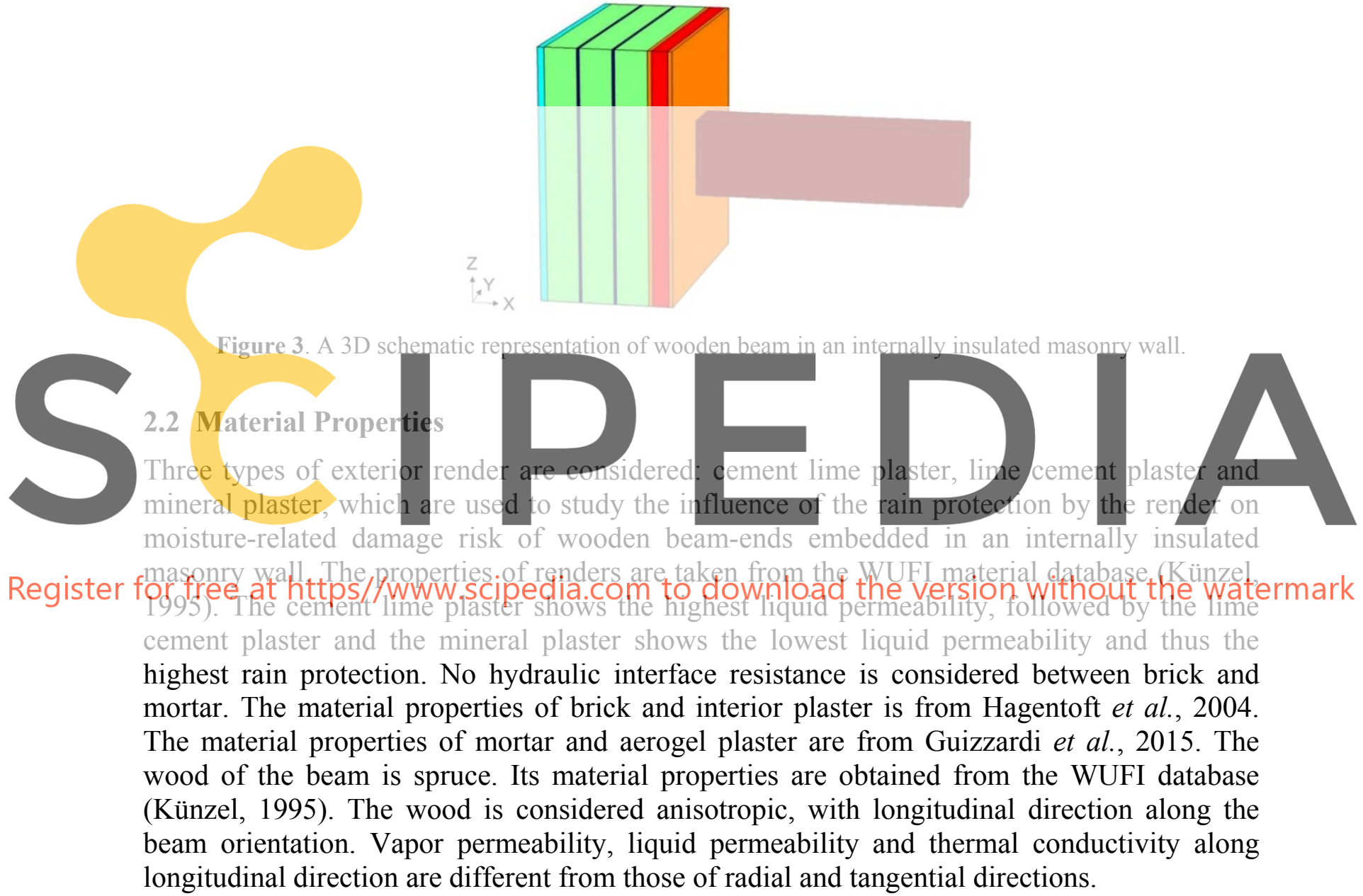

\subsection{Initial and Boundary Conditions}

The hygrothermal performance analysis is based on the moisture reference year of 1999 for Zurich (Zhou et al., 2016). This year is a wet year with a return period of 10 years. The selected wall orientation is 240 degrees from north (WSW), which shows the highest risk for moisture-related problems. This orientation is selected based on the procedure proposed in Zhou et al., 2016. The exterior conditions consists in hourly values of meteorological data from the MeteoSwiss meteorological station. The exterior convective heat transfer coefficient 
is calculated according to European standard EN15026. The exterior mass transfer coefficient is related to the exterior convective heat transfer by use of the Lewis analogy. The winddriven rain load on wall surface is calculated according to ASHRAE Standard 160 - Criteria for Moisture Control Design Analysis in Buildings (TenWolde, 2008). According to Künzel and Kiessl (1996), 70\% of the wind-driven rain hitting the façade stays there; the rest splashes off the surface and falls to the ground. The interior conditions are determined according to the European standard EN15026, in which the indoor air temperature and relative humidity depend linearly on the outdoor temperature. The building components have an initial temperature of $20.0{ }^{\circ} \mathrm{C}$ and relative humidity of $60 \%$. The simulation is started from October 1 st, and repeated for 8 years. The results of the 8 th year, which are found to be independent from the initial conditions, are used for further analysis.

\subsection{Governing Equation for Moisture and Heat Transport}

The three-dimensional governing equations for coupled moisture and heat transport in the building wall envelopes are the following [17]:

$$
\frac{\partial w}{\partial p_{c}} \frac{\partial p_{c}}{\partial t}+\nabla \cdot\left(\mathrm{g}_{l}+\mathrm{g}_{v}\right)=0
$$

with

$$
\text { liquid flow: } g_{l}=-K_{l x} \cdot \nabla p_{c}-K_{l y} \cdot \nabla p_{c}-K_{l z} \cdot \nabla p_{c}
$$

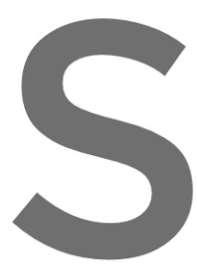

Vapor flow:
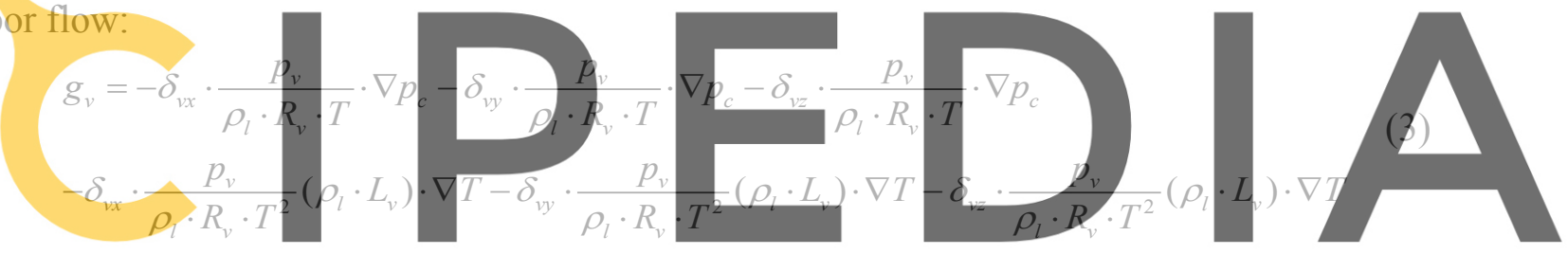

$\left(c_{0} \cdot \rho_{0}+c_{l} \cdot w\right) \cdot \frac{\partial T}{t}+\nabla \cdot\left(c_{l} \cdot\left(T-T_{r e f}\right) \cdot g_{l}+\left(c_{v} \cdot\left(T-T_{r e f}\right)+L_{v}\right) \cdot g_{v}=-\nabla\left(\lambda_{x} \nabla T+\lambda_{y} \nabla T+\lambda_{z} \nabla T\right)\right.$ Register for free at https//www.scipedia.com to download the version without the watermark where $w$ is the moisture content $\left(\mathrm{kg} / \mathrm{m}^{3}\right), p_{c}$ is the capillary pressure $(\mathrm{Pa}), \mathrm{g}_{l}$ and $\mathrm{g}_{v}$ are the

liquid and vapor flow $\left(\mathrm{kg} / \mathrm{m}^{2} \mathrm{~s}\right), K_{l x}, K_{l y}$ and $K_{l z}$ are the liquid permeability in the $\mathrm{x}, \mathrm{y}$ and $\mathrm{z}$ direction (s), $\delta_{v x}, \delta_{v y}$ and $\delta_{v z}$ are the water vapor permeability in the $\mathrm{x}, \mathrm{y}$ and $\mathrm{z}$ direction (s), $p_{v}$ is the vapor pressure $(\mathrm{Pa}), \rho_{l}$ is the density of water $\left(\mathrm{kg} / \mathrm{m}^{3}\right), R_{v}$ is the gas constant of water $(\mathrm{J} / \mathrm{kg} \mathrm{K}), T$ is the temperature $(\mathrm{K}), c_{0}$ is the specific heat capacity of solids $(\mathrm{J} / \mathrm{kg} \mathrm{K}), c_{l}$ is the specific heat capacity of water $(\mathrm{J} / \mathrm{kg} \mathrm{K}), c_{v}$ is the specific heat capacity of vapor $(\mathrm{J} / \mathrm{kg}$ $\mathrm{K}), \rho_{0}$ is the density of solids $\left(\mathrm{kg} / \mathrm{m}^{3}\right), \mathrm{T}_{r e f}$ is the reference temperature $(273.15 \mathrm{~K}), L_{v}$ is the latent heat of vaporization $(\mathrm{J} / \mathrm{kg}), \lambda_{x}, \lambda_{y}$ and $\lambda_{z}$ are the thermal conductivity in the $\mathrm{x}, \mathrm{y}$ and $\mathrm{z}$ direction $(\mathrm{W} / \mathrm{mK})$. For two-dimensional model, the variables in the $\mathrm{Y}$ direction is neglected. 


\section{Results}

\subsection{Comparison of Results Between Detailed and Simplified 2D Model}

The simulated results are given for three selected positions at the wooden beam of the 2D detailed and simplified models. The three positions are points A, B and C shown in Fig. 1 and 2. Point $\mathrm{A}$ is located next to the air gap in front of the wooden beam. Points $\mathrm{B}$ and $\mathrm{C}$ are located on the top of the wooden beam in contact with the masonry wall. Point B is located slightly more to the inside compared to Point C. Although the distribution of bricks and mortar joints is different between the detailed and simplified 2D models, the relative humidities are very close between these two models (Figure 4). For render of cement lime plaster and mineral plaster, the largest difference in relative humidity between the two models is less than 0.01 . For render of lime cement plaster, the largest difference of relative humidity is less than 0.02 . For all the three renders, the relative humidities are almost the same between the two models at Point C. In general, the relative humidity from the simplified 2D model is slightly higher during the cold period, whereas it is slightly lower during the warm period. As the moisture-related damage such as mould growth occurs in the cold period, the result from simplified 2D model will be slightly conservative compared to the detailed model. The difference of temperature between different points is very small. The largest difference in temperature is less than $0.1 \mathrm{~K}$. Considering the small difference of relative humidity and temperature between the simplified and detailed 2D model, simplification of the detailed

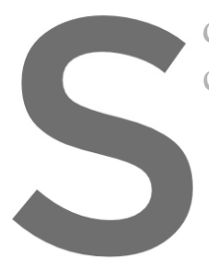
distribution of brick an can well represent the
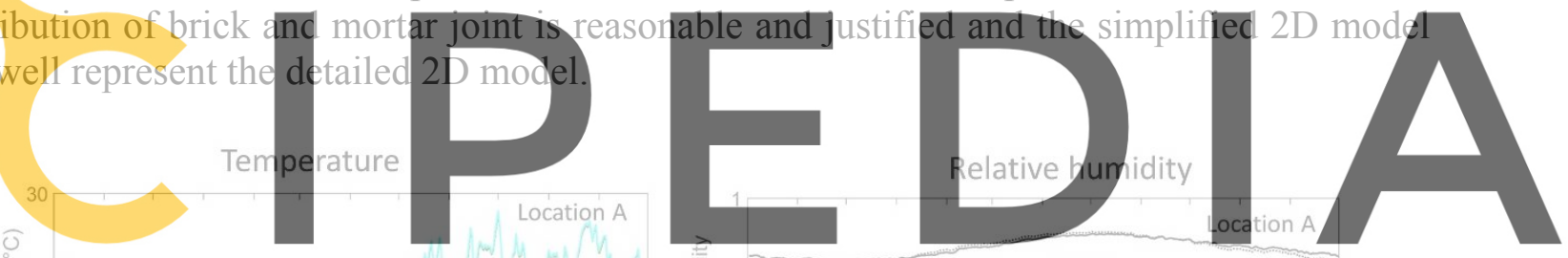

Register for free at https//www.scipedia.com to download the version without the watermark
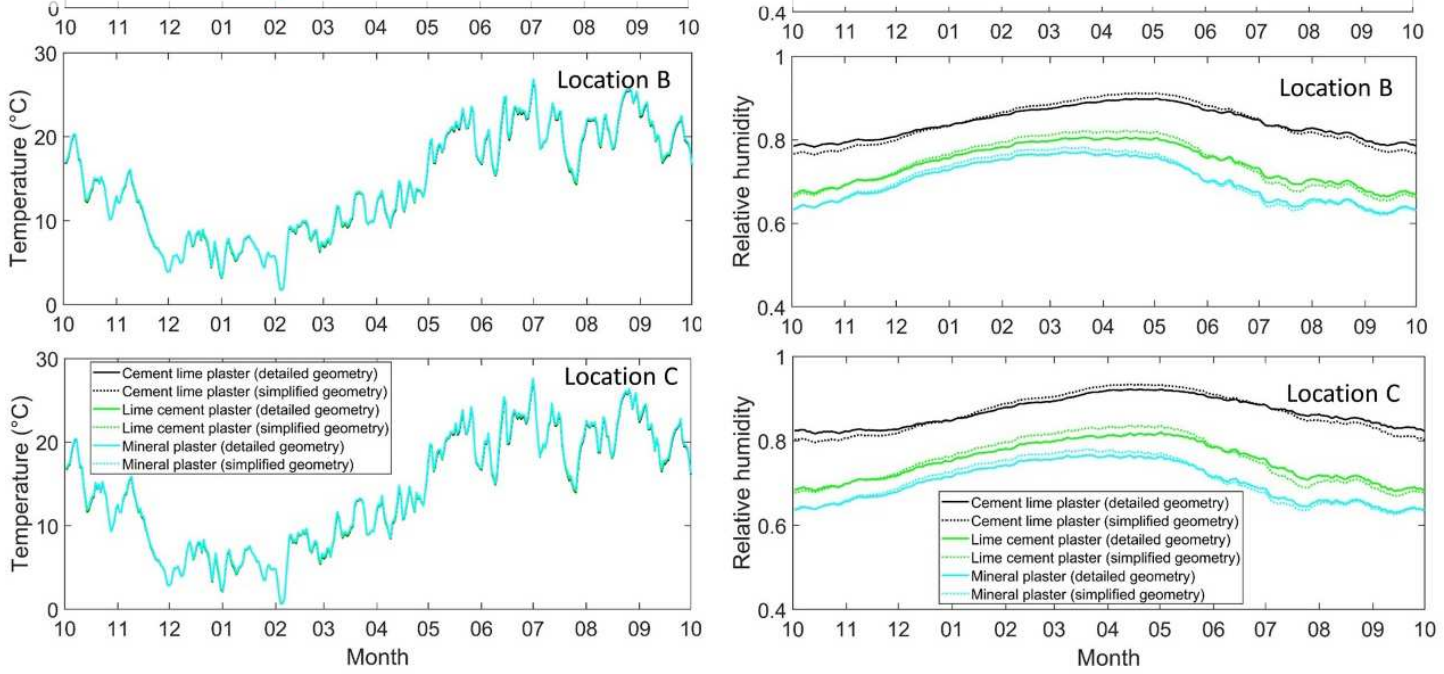

Figure 4. Temperature and relative humidity at Point A, B and C in detailed and simplified 2D model. 


\subsection{Comparison of Results Between 2D and 3D Model}

\subsubsection{Comparison of Temperature}

In $3 \mathrm{D}$ we consider the real width of the wooden beam of $20 \mathrm{~cm}$, while in $2 \mathrm{D}$ the wooden beam covers the total width of the wall. Although wood has rather low thermal conductivity, it is still much larger than that of aerogel plaster. Therefore, the wooden beam works as a kind of thermal bridge in the internally insulated masonry wall. Due to the higher heat flux in the beam, the middle cross section of the wooden beam embedded in masonry wall will be warmest cross section of the wooden beam during winter period, while the outermost surface in contact with masonry wall will be the coldest one. So, we consider the temperature in the points $\mathrm{A}, \mathrm{B}$ and $\mathrm{C}$ in the middle section and in the surface in contact with the masonry (called outermost cross section). In general, there are some differences of temperature between the 2D and 3D models (Fig. 5). The temperature in the 2D cross section is the highest. The higher temperature in the 2D cross section is due to larger width of wooden beam and thus larger thermal bridge effect in the 2D model. The largest temperature difference at points A, B and $\mathrm{C}$ between the $2 \mathrm{D}$ and $3 \mathrm{D}$ cross sections is $1.08 \mathrm{~K}$, while the smallest one is $0.02 \mathrm{~K}$. In the $3 \mathrm{D}$ model, the temperature from the center cross section is higher than that in the outermost cross section. The largest temperature difference at points $\mathrm{A}, \mathrm{B}$ and $\mathrm{C}$ between the 3D middle and $3 \mathrm{D}$ outermost cross sections is $0.46 \mathrm{~K}$, while the smallest one is $0.02 \mathrm{~K}$.
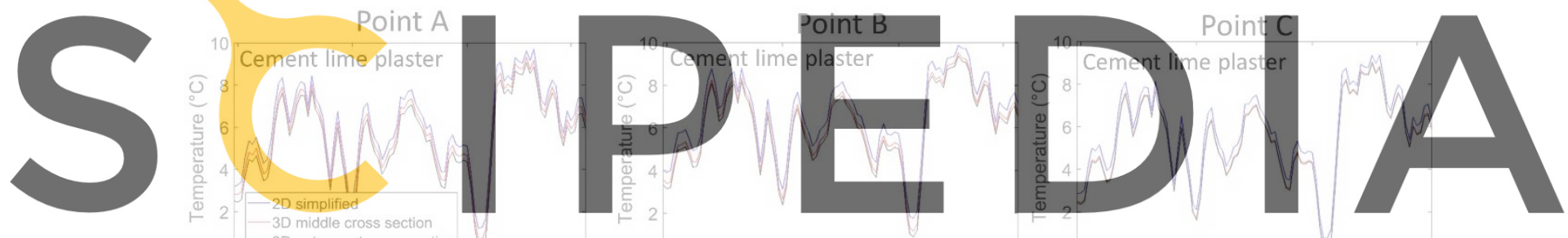

Register for free at https//WWww.scipedia.com to downiload the version without the watermark
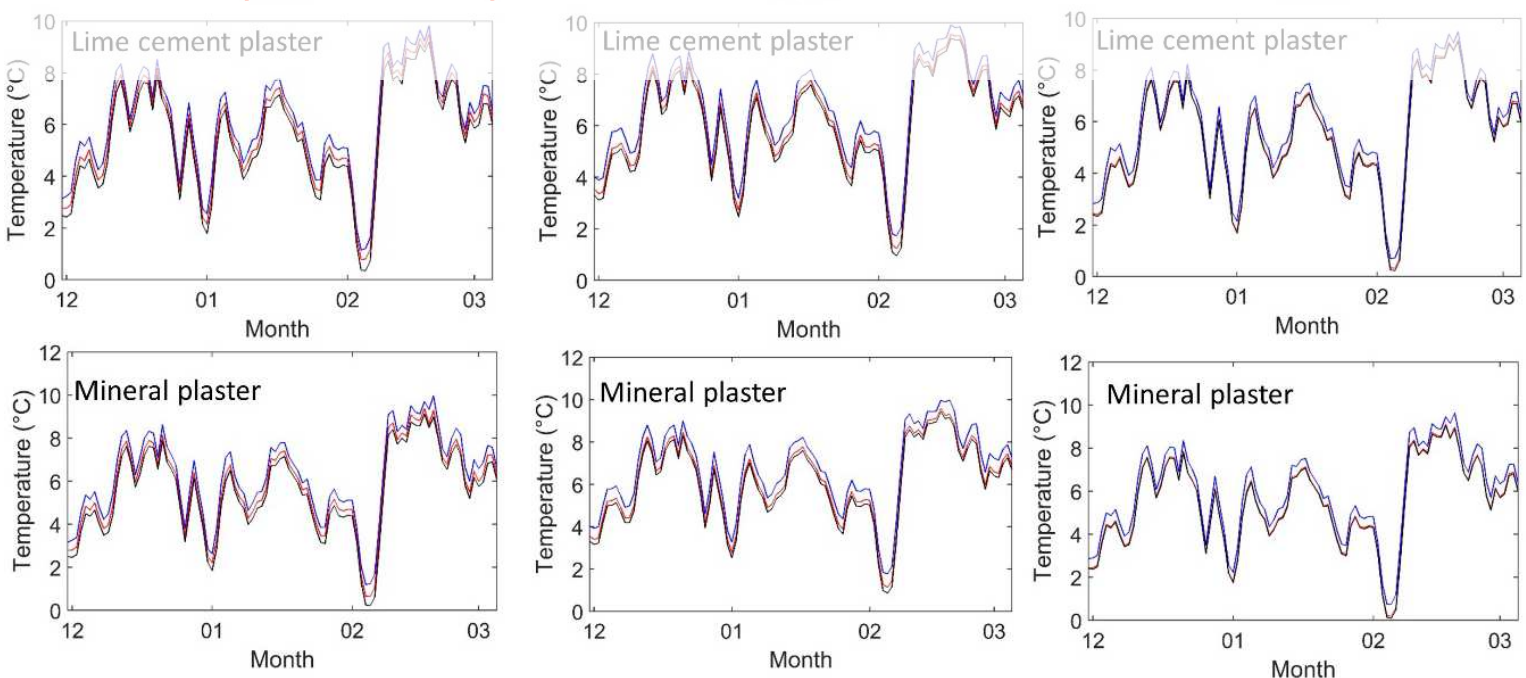

Figure 5. Temperature at Points A, B and C in simplified 2D model and middle and outermost cross section of the 3D model in winter period. 


\subsubsection{Comparison of relative humidity}

The differences in relative humidity among different cross sections is large at point A (Figure 6). The largest difference is in the wall envelope with mineral plaster (low liquid permeability), which can reach 0.06 . In general, the fluctuation of relative humidity at the outermost cross section of the 3D model is larger than at the central cross sections, especially during the cold periods. Relative humidity at point $\mathrm{A}$ at the central and outermost cross sections is quite different whereas relative humidity at points $\mathrm{B}$ and $\mathrm{C}$ at the central and outermost cross sections is very close. For the wall envelope with mineral plaster, relative humidity at point $\mathrm{A}$ is continuously below 0.8 in the $2 \mathrm{D}$ model while it can be above 0.8 continuously from February to June at the outermost cross section in the $3 \mathrm{D}$ model. The $2 \mathrm{D}$ model will in general underestimate to some extent the moisture risk compared to 3D model. If the study is to have accurate relative humidity in the wooden beam-end, it is not appropriate to replace a $3 \mathrm{D}$ model with a $2 \mathrm{D}$ one.

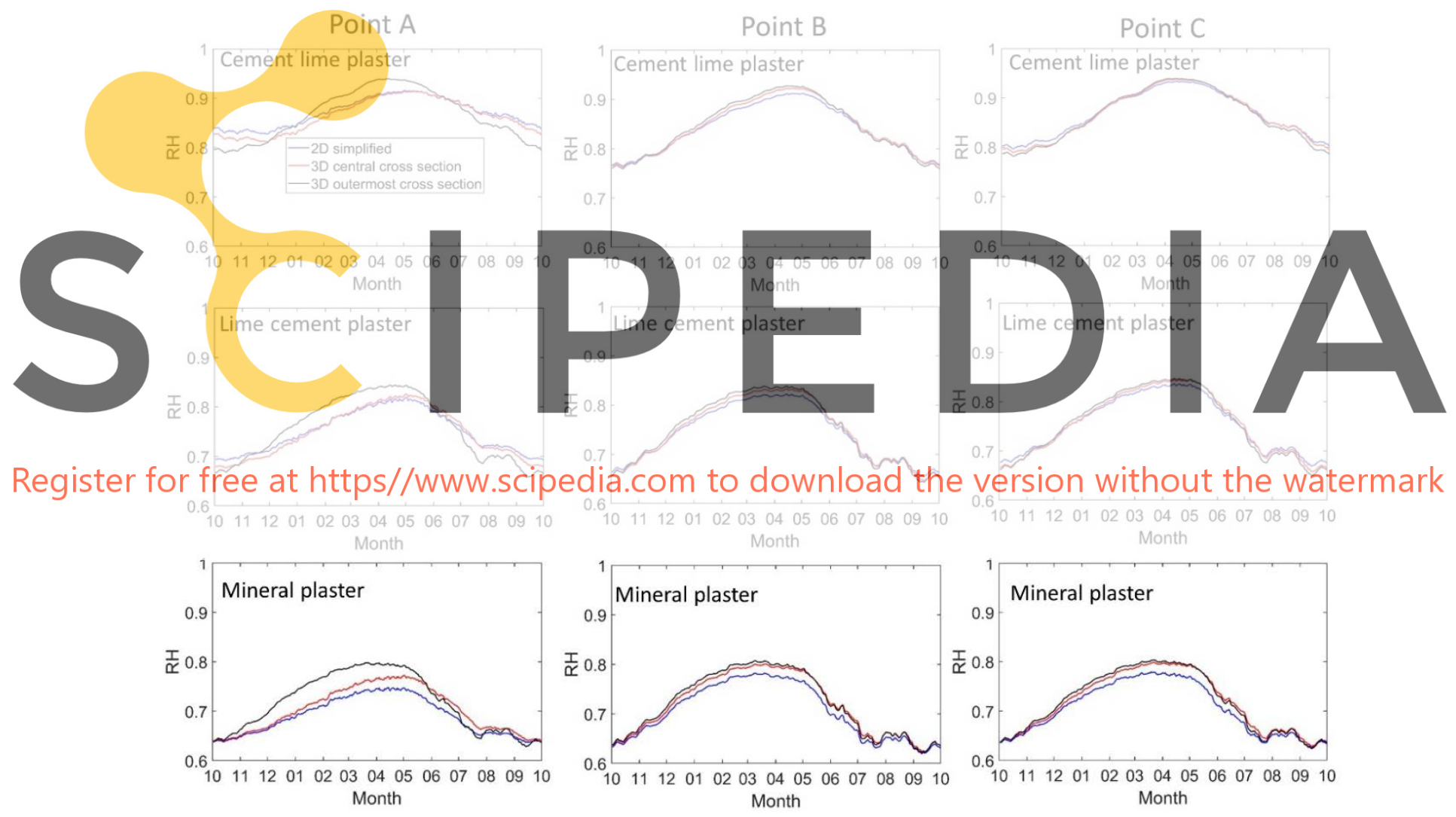

Figure 6. Relative humidity at Points A, B and C in simplified 2D model and central and outermost cross section of the 3D model.

\section{Conclusions}

- The hygrothermal performance of a wooden beam-end embedded in an internally insulated masonry wall is analyzed using 2D and 3D hygrothermal models.

- The difference of temperature and relative humidity in wooden beam-end between 2D 
and 3D models is in general small. However, 2D hygrothermal models show much lower relative humidities and thus lower moisture risk at some locations in the wooden beam-end. In general, a 3D hygrothermal model can more accurately represent the hygrothermal condition than the $2 \mathrm{D}$ one.

\section{Acknowledgements}

This research project is part of the Swiss Competence Center for Energy Research SCCER FEEB\&D of the Swiss Innovation Agency Innosuisse. The meteorological data have been provided by MeteoSwiss, the Swiss Federal Office of Meteorology and Climatology.

\section{ORCID}

Xiaohai Zhou: https://orcid.org/0000-0002-8291-250X

Jan Carmeliet: https://orcid.org/0000-0003-2186-963X

Dominique Derome: https://orcid.org/0000-0002-8018-1133

References

Guizzardi, M., Carmeliet, J. and Derome, D. (2015). Risk analysis of biodeterioration of wooden beams embedded in internally insulated masonry walls. Construction and Building Materials, 99, 159-168.

Guizzardi, M., Derome, D., Vonbank, R. and Carmeliet, J. (2015). Hygrothermal behavior of a massive wall with interior insulation during wetting, Building and Environment, 89, 59-71.

Hagentoft, C.-E., Kalagasidis, A.S., Adl-Zarrabi, B., Roels, S., Carmeliet, J. and Hens, H., et al., (2004). Assessment method of numericai prediction models for combined heat, air and moisture transfer in building components: benchmark fo

Harrestrup, M., and Svend wooden beams embedde

Johansson, P., Geving, S. Interior insulation retrofi
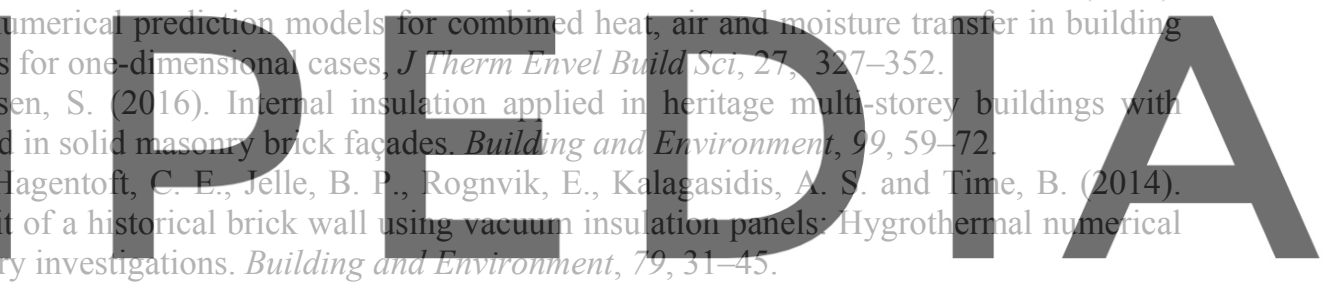

Kehl, D., Ruisinger, U., Plagge, R. and Grunewald, J. (2013). Wooden beam ends in masonry with interior

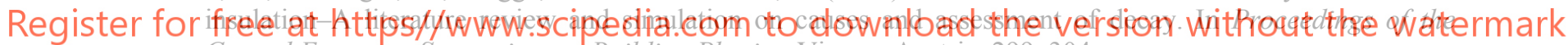
Central European Symposium on Building Physics, Vienna, Austria, 299-304.

Künzel, H.M. Simultaneous Heat and Moisture Transport in Building Components, [PhD thesis] 1995 University of Stuttgart.

Künzel, H. M. and Kiessl, K. (1996). Calculation of heat and moisture transfer in exposed building components. International Journal of Heat and Mass Transfer, 40(1), 159-167.

Künzel, H. M., Künzel, H. and Holm, A. (2004). Rain protection of stucco facades. In Proceedings of the Thermal Performance of the Exterior Envelopes of Whole Buildings IX-International Conference, Florida, USA, $1-7$

Morelli, M. and Svendsen, S. (2013). Investigation of interior post-insulated masonry walls with wooden beam ends. Journal of Building Physics, 36(3), 265-273.

Pazera, M. and Bomberg, M. (2010). Applying Lessons from Clay-Brick Veneer to Design a Stucco Mix. In Proceedings of the BEST Conference Building Enclosure Science and Technology, Portland, USA, 1-17.

TenWolde, A. (2008). ASHRAE Standard 160P--criteria for moisture control design analysis in buildings.

Zhou, X., Carmeliet, J. and Derome, D. (2018). Influence of envelope properties on interior insulation solutions for masonry walls. Building and Environment, 135, 246-256.

Zhou, X., Derome, D. and Carmeliet, J. (2016). Robust moisture reference year methodology for hygrothermal simulations. Building and Environment, 110, 23-35.

Zhou, X., Derome, D. and Carmeliet, J. (2017). Hygrothermal modeling and evaluation of freeze-thaw damage risk of masonry walls retrofitted with internal insulation. Building and Environment, 125, 285-298 